\begin{tabular}{|c|c|c|}
\hline & 1) Accredited course & 2) Placement option \\
\hline Duration & One week full time & $\begin{array}{l}\text { - Two induction days } \\
\text { - One evening per week for six } \\
\text { months }\end{array}$ \\
\hline Staff resource & Two facilitators - full time & $\begin{array}{l}\text { - Induction facilitator } \\
\text { - Mentor - providing observations } \\
\text { in practice }\end{array}$ \\
\hline $\begin{array}{l}\text { Maximum yearly } \\
\text { capacity }\end{array}$ & 24 & 28 \\
\hline Activities & $\begin{array}{l}\text { - Interview multi-professional } \\
\text { staff } \\
\text { - Engage with patients in day } \\
\text { therapy }\end{array}$ & $\begin{array}{l}\text { - Shadow ward staff } \\
\text { - Interact with patients on ward }\end{array}$ \\
\hline $\begin{array}{l}\text { Potential } \\
\text { qualifications }\end{array}$ & $\begin{array}{l}\text { City and Guilds: } \\
\text { 1) Employability } \\
\text { 2) Understand social care } \\
\text { 3) Awareness of end-of-life } \\
\text { care }\end{array}$ & 1) Care certificate \\
\hline
\end{tabular}

A student's conclusion - "I was relieved to find out we were being taught valuable skills on an actual course, not just making teas.”

Conclusion From successful pilot, we expect the following outcomes to shape future training:

- Increase in students accessing and considering a career in care

- Identify best approach to support students

- Portable qualifications achieved

- Focused opportunity for staff to support students.

\section{P-240 PEOPLE, PARTNERSHIPS AND POTENTIAL - A COLLABORATIVE TEACHING PROJECT BETWEEN CYPRUS AND A UK HOSPICE}

Caroline Archibald, Faith Rylands, Kate Shorthose, Maxine Smith. St Margaret's Hospice, Taunton, UK

\subsection{6/bmjspcare-2016-001245.261}

Introduction In 2015 in Cyprus a family member became unwell and needed medical assistance, which led to a palliative care nurse crossing paths with a Cypriot Hospice.

An extended invitation to come and visit the hospice, meet the staff and talk about the role of a palliative care nurse working in the UK. This resulted in a request to develop formalised education programme and to return to Cyprus to provide teaching on end-of-life issues, communication and symptom control. This has resulted in ongoing teaching collaboration.

Aims

- To offer training to the multidisciplinary team on end of life issues, communication and symptom control issues through modelling, sharing skills and knowledge

- Sharing good practice

- Offering peer support

- Sharing our experiences with staff and volunteers working at a Cypriot hospice and within our own UK hospice

- Empowering the Cypriot nurses through up to date knowledge on issues in palliative care.

Method

- Communication via skype and regular email contact
- A fact finding mission

- Delivery of tailored teaching programmes on end of life issues, communication and symptom control issues to the hospice nurses and doctors in Cyprus

- Two Cypriot nurses released to shadow colleagues working in the UK hospice. They will then cascade the knowledge, skills and experience they have gained when they return to Cyprus.

Conclusion

- Positive feedback from the doctors and nurses on the benefits of the teaching and impact on care delivery

- A rolling rota planned for the Cypriot nurses to come over and gain experience of working alongside our nurses

- Ongoing collaboration between the two hospices

- Awareness and respect for the cultural and economic differences in end-of-life care delivery

- Learning and sharing of experience for UK nurses of the challenges within other healthcare settings.

\section{P-241 FOUNDATION DOCTORS EXPERIENCES OF DISCUSSING CPR}

${ }^{1}$ Alexandra Hadjimichalis, ${ }^{1,2}$ Pauline Dand. ${ }^{1}$ East Kent University Hospitals Foundation Trust, Kent, UK; ${ }^{2}$ Pilgrims Hospices, Kent, UK

\subsection{6/bmjspcare-2016-001245.262}

Background Appropriate, anticipatory cardiopulmonary resuscitation (CPR) discussions and decisions are now an integral part of good clinical practice, and have been shown to reduce futile treatment and end-of-life distress.

CPR decisions have been established to rest with the most senior clinician, yet our hospital experience suggests that even the most junior of doctors can be involved in this process. For doctors in training this can represent one of the most difficult ethico-legal challenges they face, with reports of lack of confidence and formal teaching.

Aims The aim of the study was to explore our most junior doctors' - 'foundation doctors' - experiences of discussing CPR with hospital in-patients and their relatives; to identify any training needs, and if required design and deliver an appropriate training intervention.

Methods An electronic survey using a semi-structured questionnaire was distributed to 118 foundation doctors working in East Kent University Hospital Foundation Trust. Simple percentage analysis of results was undertaken.

Results Response rate to the questionnaire was $45 \%$. The majority of respondents did have experience of discussing CPR with patients/relatives, with 69\% [31/45] reporting initiating such a discussion. A third of these doctors felt inadequately prepared for such discussions ['not prepared' or only 'a little prepared']. Many found the discussion difficult [34/40] and nearly half [18/40] found it distressing to some degree. Only a minority [6/45] reported having received formal postgraduate teaching on conducting CPR discussions, and most respondents [39/45] reported a need for further training.

Conclusion The majority of foundation doctors in this study had been involved in conversations about CPR. A significant number felt inadequately prepared for the task and the majority identified specific teaching and training needs. The investigators have collaborated to design an educational initiative for local foundation doctors based on identified needs which is currently being piloted. 